\title{
In vitro effect of a buffered chelating agent and neomycin or oxytetracycline on bacteria associated with diseases of fish
}

\author{
Richard E. Wooley ${ }^{1, *}$, Branson W. Ritchie ${ }^{2}$, Victoria V. Burnley ${ }^{2}$ \\ ${ }^{1}$ Department of Medical Microbiology and Parasitology, and ${ }^{2}$ Department of Small Animal Medicine and Surgery, \\ College of Veterinary Medicine, University of Georgia, Athens, Georgia 30602-7386, USA
}

\begin{abstract}
The antimicrobial agents used to treat bacterial fish diseases are archaic, and their uses may result in the emergence of drug-resistant bacterial strains. This study evaluated the in vitro antimicrobial activity of combinations of Tricide ${ }^{\mathrm{TM}}$ and neomycin or oxytetracycline on common disease-causing bacteria of fish and its possible use as an alternative treatment of these diseases. Tricide $^{\mathrm{TM}}$ solutions containing of $8 \mathrm{mM}$ United States Pharmacopeia (USP) disodium ethylenediaminetetraacetate dehydrate (chelator) and 20 mM USP 2-amino-2-hydroxymethyl-1,3-propanediol (buffer) potentate the antimicrobial action of neomycin and oxytetracycline when reacted in vitro with Aeromonas hydrophila, Streptococcus iniae, Pseudomonas aeruginosa, and Staphylococcus aureus. Serial passage of the test organisms in Tricide ${ }^{\mathrm{TM}}$ or Tricide $^{\mathrm{TM}}$ and neomycin or oxytetracycline did not result in the development of resistant forms. Combinations of Tricide ${ }^{\mathrm{TM}}$ and neomycin or oxytetracycline reduced the amount of antibiotics necessary for fish therapy, render drug-resistant bacteria sensitive to antimicrobial therapy, may be used to decontaminate recently shipped fish, and should reduce the formation of antibiotic-resistant forms.
\end{abstract}

KEY WORDS: Tricide ${ }^{\mathrm{TM}} \cdot$ Aquatic infections $\cdot$ Topical treatment $\cdot$ Chelation

Resale or republication not permitted without written consent of the publisher

\section{INTRODUCTION}

Ornamental fish may develop acute systemic and/or chronic granulomatous diseases, where the bacteria may cause damage to the fins and ulcerations of the skin. These infections may be caused by primary pathogens, but more commonly are due to stressinduced secondary infections. Clinical signs include lethargy, erythema and petechiation of the skin and fins, along with ulcerations of the skin, and internal lesions. These lesions are most commonly associated with Gram-negative organisms such as Aeromonas, Pseudomonas, Vibrio, Flavobacteria, Yersinia, and Edwardsiella spp. Gram-positive infections caused by streptococci are also observed as epizootics in warm-

*Email: wooleyr@vet.uga.edu water species (Butler 1993). Streptococcus iniae is an emerging bacterial pathogen in cultured and freeranging fish (Shao 2001). The highest mortality levels occur in cultured fish (Weaver-Missick 1999). Antibiotics are currently used to control the streptococcal disease, which causes worldwide losses of $\$ 150$ million $\mathrm{yr}^{-1}$ (McNulty et al. 2002).

The chemical and antimicrobial agents used in treating fish diseases are rather archaic. The primary means of administration is via water, medicated feed, and injection (Stuart 1983). The use of antibiotics alone may result in residues, such as tetracycline (Shao 2001), and the emergence of drug-resistant bacterial strains, which may transfect humans (Stuart 1983). 
There is growing concern over the increase in multidrug-resistant bacteria in human and veterinary medicine (Bryan 1984). Bacteria may become resistant to antibiotics by cellular resistance, antibiotic efflux pumps, and the presence of antibiotic-degrading and deactivating enzymes (Fluit et al. 2001). The control of infections, and in particular those in cultured fish, would be facilitated through the use of agents that physically damage the bacterium beyond the point at which it can successfully repair itself.

Cell surfaces of Gram-negative bacteria are damaged by exposure of cells to disodium ethylenediaminetetraacetate dehydrate (chelator) and 2-amino2-hydroxymethyl-1, 3-propanediol (buffer) (Goldschmidt $\&$ Wyss 1967, Roberts et al. 1970) resulting in increased permeability (Leive 1968) and greater sensitivity to bactericides and antibiotics (Brown \& Richards 1965, Monkhouse \& Graves 1967, Russel 1967, Wooley \& Jones 1983). The chelator removes divalent cations present in the outer membrane (Leive et al. 1968) altering the integrity and permeability of the outer membrane with the release from the bacterial cell of periplasmic enzymes, cell membrane-associated proteins (Heppel 1972), lipopolysaccharide (Bayer \& Leive 1977), protein, and phospholipids (Leive et al. 1968). Solutions of the chelator have also been shown to dissolve the biofilm produced by Pseudomonas aeruginosa (Krieg et al. 1988). Synergistic antimicrobial effects have been demonstrated when combinations of the chelator-buffer and selected antimicrobial agents were reacted with Gram-negative bacteria (Gerberick \& Castric 1980, Wooley \& Jones 1983, Wooley et al. 1983a,b, 1984a, Farca et al. 1993, Sparks et al. 1994). Gram-negative bacteria exposed to chelator-buffer solutions have an increased uptake of radio-labeled antibiotics (Wooley et al. 1984b).

Combinations of chelator-buffer and antibiotics have been found to be effective in the treatment of coliform infections of the urinary bladder (Goldschmidt et al. 1972), bacterial rhinitis in dogs (Wooley et al. 1979), Pseudomonas cystitis (Wooley et al. 1974), otitis externa (Blue et al. 1974, Sparks et al. 1994), multiple fistulas (Ashworth \& Nelson 1990, Bjorling \& Wooley 1982) in dogs, and metritis in the mare (Youngquist 1975, Youngquist et al. 1984). The addition of chelatorbuffer into commercially available mastitis medications also resulted in a potentiation of the in vitro antimicrobial effect of the medication (Wooley et al. 2002).

Solutions of chelator-buffer with and without the addition of antimicrobial agents have antimicrobial properties on Gram-positive cocci (Wooley \& Jones 1983, Sparks et al. 1994). Although to a lesser degree, potentiation of antibiotics by the chelator-buffer was also observed for Gram-positive rod-shaped bacteria
(Wooley \& Blue 1975, Wooley \& Jones 1983, Wooley et al. 1983c).

Chelator-buffer solutions at concentrations 10-times those in Tricide ${ }^{\mathrm{TM}}$ are nontoxic when injected into the allantoic cavity of 12 d-old chicken embryos, and 5 serial passages of Staphylococcus aureus, Proteus mirabilis, Pseudomonas aeruginosa, Salmonella enteritidis, S. typhimurium and Bacillus subtilis in these solutions did not result in the development of resistant forms (Wooley et al. 2000). No clinical side-effects have been noted using this solution in joints, bones, uterus, ears, bladders, mammary glands, or uterus of humans, poultry, companion animals and domestic livestock (Goldschmidt et al. 1972, Bjorling \& Wooley 1982, Youngquist et al. 1984, Ashworth \& Nelson 1990, Sparks et al. 1994).

The purpose of this study was to evaluate the in vitro antimicrobial activity of Tricide ${ }^{\mathrm{TM}}$ and neomycin or oxytetracycline on bacteria associated with diseases of fish.

\section{MATERIALS AND METHODS}

Bacterial isolates. Bacterial isolates used in this study were cultured from diseased fish. Staphylococcus aureus was cultured from an ulcerated lesion on the koi Cytrinus carpio. Pseudomonas aeruginosa was isolated from the kidneys of a septicemic koi. Streptococcus iniae (Isolate DAN 14) was isolated from the brain of a diseased coho salmon Oncorhynchus kisutch. Aeromonas hydrophila (Isolate 5064) was cultured from an ulcerated lesion on a koi. $S$. aureus and $S$. iniae (Isolate DAN14) were propagated in/on brain heart infusion (BHI) broth or agar (DifCo). $P$. aeruginosa and $A$. hydrophila (Isolate 5046) were propagated in BHI broth and/or MacConkey agar. Isolates were incubated at $35^{\circ} \mathrm{C}$. Bacterial isolates were stored at $-70^{\circ} \mathrm{C}$.

Reference strains. Reference strains (American Type Culture Collection) were used to monitor the in vitro procedures as recommended by the National Committee for Clinical Laboratory Standards (NCCLS 1999). The strains included Escherichia coli (ATCC\# 25922), Pseudomonas aeruginosa (ATCC\# 27853), Enterococcus faecalis (ATCC\# 29212), and Staphylococcus aureus (ATCC\#25923).

Tricide $^{\mathrm{TM}}$. The Tricide ${ }^{\mathrm{TM}}$ formula consists of $8 \mathrm{mM}$ USP disodium ethylenediaminetetraacetate dehydrate (chelator) (Research Genetics) and 20 mM USP 2-amino2-hydroxymethyl-1,3-propanediol (buffer) (Sigma). Neomycin sulfate (Pharmacia and Upjohn) or oxytetracycline $\mathrm{HCl}$ (Pfizer) was added at a concentration of $500 \mathrm{mg} \mathrm{l}^{-1}$ to the Tricide ${ }^{\mathrm{TM}}$ solution.

Antibiotic resistance profiles. Antibiotic resistance profiles were determined by the disc-diffusion method 
Table 1. Antibiotic resistance profiles of 4 test organisms. AM = ampicillin; $\mathrm{CM}=$ chloramphenicol $; \mathrm{GM}=$ gentamicin $; \mathrm{KN}=$ kanamycin $; \mathrm{NE}=$ neomycin; NA = nalidixic acid $; \mathrm{ST}=$ streptomycin $; \mathrm{SU}=$ sulfasoxazole $; \mathrm{TE}=$ tetracycline; $\mathrm{R}=$ resistant; $\mathrm{I}=$ intermediate; $\mathrm{S}=$ susceptible. In vitro intermediate sensitivity is considered clinically resistant

\begin{tabular}{|lllllllllll|}
\hline \multirow{2}{*}{ Organism } & \multicolumn{1}{c|}{ Antimicrobial agent } \\
& AM & CM & GM & KN & NE & NA & ST & SU & TE \\
\hline Pseudomonas aeruginosa & R & R & I & R & R & R & R & R & R \\
Staphylococcus aureus & R & S & S & R & R & R & I & R & S \\
$\begin{array}{c}\text { Aeromonas hydrophila } \\
\quad \text { Isolate 5046) }\end{array}$ & R & S & S & S & S & S & S & R & S \\
$\begin{array}{c}\text { Streptococcus iniae } \\
\quad \text { Isolate DAN 14) }\end{array}$ & S & R & R & R & R & R & R & R & R \\
\hline
\end{tabular}

cide $^{\mathrm{TM}}$ with neomycin or oxytetracycline in BHI broth. Tubes were incubated at $35^{\circ} \mathrm{C}$ for 18 to $24 \mathrm{~h}$. The tube containing the highest concentration of Tricide ${ }^{\mathrm{TM}}$ or Tricide $^{\mathrm{TM}}$ with antibiotic that showed growth was used to inoculate another set of tubes also containing 2-fold dilutions in BHI broth. This process was repeated until a resistant mutant was obtained or up to a limit of 5 serial passages (Wooley et al. 2000).

\section{RESULTS}

on Mueller-Hinton agar plates (NCCLS 1999, Walker 2000). Antibiotics tested included ampicillin, chloramphenicol, kanamycin, gentamicin, nalidixic acid, neomycin, streptomycin, sulfasoxazole, and tetracycline.

Minimum inhibitory concentration (MIC) and minimum bactericidal concentration (MBC). MICs for the test formulations were determined by the microtiter broth dilution susceptibility test (Forbes et al. 1998, NCCLS 1999, Walker 2000). Approximately $5 \times 10^{5}$ colony-forming units (CFU) $\mathrm{ml}^{-1}$ (NCCLS 1999) of the test organism in $50 \mu \mathrm{l}$ of BHI broth were added to microtiter wells containing serial 2-fold dilutions of the antimicrobial solutions $(50 \mu \mathrm{l})$ in BHI broth. Plates were incubated at $35^{\circ} \mathrm{C}$ with shaking (100 rpm) for 24 and $48 \mathrm{~h}$ and the results of growth used to determine the MIC values. Determination of MBCs was made by the inoculation of $10 \mu \mathrm{l}$ from each well of the microtiter plates onto appropriate agar plates. The plates were incubated at $35^{\circ} \mathrm{C}$ and examined for bacterial growth after 24 and $48 \mathrm{~h}$ (Forbes et al. 1998).

Antibacterial efficacy tests. Three samples of Tricide $^{\mathrm{TM}}$ and 1 sample of Tricide ${ }^{\mathrm{TM}}$ with neomycin were compared to laboratory standard solutions with the same concentrations of chelator, buffer, and neomycin. The Tricide ${ }^{\mathrm{TM}}$ samples and the laboratory standard were inoculated with the 4 test organisms in the microtiter MIC format. End-points were then compared after incubation overnight.

pH values. $\mathrm{pH}$ values were calculated on a Thermo Orion LogR temperature-compensated $\mathrm{H}$ meter over a $9 \mathrm{~d}$ period in order to determine the stability of Tricide $^{\mathrm{TM}}$.

Selection of resistant mutants. An attempt to induce resistant mutants to Tricide ${ }^{\mathrm{TM}}$, Tricide ${ }^{\mathrm{TM}}$ with neomycin, and Tricide ${ }^{\mathrm{TM}}$ with oxytetracycline was done by a stepwise selection technique (NCCLS 1999). The test organisms $\left(10^{6} \mathrm{CFU}\right)$ were inoculated into a series of tubes containing 2-fold dilutions of Tricide ${ }^{\mathrm{TM}}$ or Tri-
The antibiotic resistance profiles of the test organisms are presented in Table 1. Streptococcus iniae (Isolate DAN14) and Pseudomonas aeruginosa had the most antimicrobial resistances including resistance to neomycin and tetracycline. Staphylococcus aureus was resistant to 5 of the 8 antibiotics tested, including neomycin. Aeromonas hydrophila (Isolate 5046) was resistant to 2 of the 8 tested, but was sensitive to neomycin and tetracycline. The MIC and MBC values for Tricide ${ }^{\mathrm{TM}}$ reactions with the 4 test organisms are shown in Table 2. The lowest MICs were seen for $S$. iniae and $S$. aureus, while greater MICs were observed for A. hydrophila and $P$. aeruginosa. The antimicrobial activity of neomycin and oxytetracycline was potentiated when combined with sub-MIC amounts $(<50 \%$ of MIC value) of Tricide ${ }^{\mathrm{TM}}$. As shown in Table 3, the amounts of neomycin and oxyteracycline required to inhibit the growth (MIC) or kill (MBC) the 4 test organisms decreased from 50 to $99 \%$.

\section{Antibacterial efficacy tests}

The MIC and MBC values for Tricide ${ }^{\mathrm{TM}}$ and Tricide ${ }^{\mathrm{TM}}$ with neomycin were identical to those of the laboratory standard of chelator buffer with and without neomycin when tested against the 4 test organisms.

Table 2. Minimal inhibitory concentrations (MIC) and minimal bactericidal concentrations (MBC) of Tricide ${ }^{\mathrm{TM}}$ for 4 test organisms

\begin{tabular}{|lcc|}
\hline Organism & MIC Tricide $^{\mathrm{TM}}$ & $\mathrm{MBC}$ Tricide $^{\mathrm{TM}}$ \\
\hline Pseudomonas aeruginosa & $1.0 \times$ & $2.0 \times$ \\
Staphylococcus aureus & $0.125 \times$ & $1.0 \times$ \\
$\begin{array}{l}\text { Aeromonas hydrophila } \\
\text { (Isolate 5046) }\end{array}$ & $0.25 \times$ & $0.25 \times$ \\
$\begin{array}{l}\text { Streptococcus iniae } \\
\text { (Isolate DAN 14) }\end{array}$ & $0.125 \times$ & $>5.0 \times$ \\
\hline
\end{tabular}


Table 3. Percent decrease in concentrations of neomycin and oxytetracycline when combined with sub-MIC (minimal inhibitory concentrations) amounts of Tricide ${ }^{\mathrm{TM}}$ resulting in inhibition of bacterial growth (MIC) or killing (minimal bactericidal concentrations: $\mathrm{MBC}$ ) of the 4 test organisms

\begin{tabular}{|c|c|c|c|c|}
\hline \multirow{2}{*}{ Organism } & \multicolumn{2}{|c|}{ Neomycin } & \multicolumn{2}{|c|}{ Oxytetracycline } \\
\hline & MIC & $\mathrm{MBC}$ & MIC & MBC \\
\hline Pseudomonas aeruginosa & 90 & 90 & 90 & 99 \\
\hline Staphylococcus aureus & 96 & 99 & 50 & 92 \\
\hline $\begin{array}{l}\text { Aeromonas hydrophila } \\
\quad \text { (Isolate 5046) }\end{array}$ & 50 & 50 & 97 & 99 \\
\hline $\begin{array}{l}\text { Streptococcus iniae } \\
\text { (Isolate DAN 14) }\end{array}$ & 99 & 92 & 99 & 96 \\
\hline
\end{tabular}

\section{pH stability}

Initially, the 3 samples of Tricide ${ }^{\mathrm{TM}}$ and 1 of Tricide ${ }^{\mathrm{TM}}$ with neomycin had the following $\mathrm{pH}$ values: 8.03, 8.03, 7.97 , and 7.84, respectively. A reconstituted sample of Tricide $^{\mathrm{TM}}$ stored at room temperature had the following $\mathrm{pH}$ values over a $9 \mathrm{~d}$ period: $7.68,7.68,7.65,7.72,7.72$, $7.64,7.67,7.70$, and 7.67 , showing the stable nature of the compound.

\section{Selection of resistant mutants}

No resistant mutants to solutions of Tricide ${ }^{\mathrm{TM}}$ or combinations of Tricide ${ }^{\mathrm{TM}}$ with neomycin or oxytetracycline developed after 5 serial passages.

\section{DISCUSSION}

The premise that antibiotic resistance is developing in microorganisms (Fluit et al. 2001), along with other mechanisms such as the development of biofilms by Pseudomonas aeruginosa (Krieg et al. 1988), makes the control of bacterial infections with antimicrobial agents that react at the structural or biochemical levels more and more difficult. It is apparent that control of infections will require agents that physically damage the causative organism beyond the point that it can successfully repair itself. Tricide ${ }^{\mathrm{TM}}$ appears to meet this requisite of antimicrobial activity by physically altering bacterial cells. When Tricide ${ }^{\mathrm{TM}}$ was mixed with neomycin or oxytetracycline, the combined product had greater antibacterial action over either one used alone. The evidence that solutions of Tricide ${ }^{\mathrm{TM}}$ enhances the antimicrobial action of neomycin and oxytetracycline and reduces the potential to develop multi-drug-resistant bacteria makes these combinations an attractive alternative method for the treatment and control of superficial bacterial infections in fish.
Previous studies in our laboratory have shown that organisms that develop antibiotic resistance to neomycin or oxytetracycline when pressured with these drugs remain antibiotic-sensitive when combined with Tricide ${ }^{\mathrm{TM}}$ (authors' unpubl. data). Tricide ${ }^{\mathrm{TM}}$ with and without the addition of antimicrobial agents could be used as a prophylactic treatment of newly acquired fish before being introduced into an aquarium, and also in the treatment of fish with superficial infections in small treatment tanks. This treatment regime would be especially valuable in the prevention and treatment of bacterial diseases in ornamental fish. In summary, Tricide ${ }^{\mathrm{TM}}$, due to its potentiation of the antimicrobial action of neomycin and oxytetracycline, makes bacteria that are resistant to these drugs susceptible; it is pH-stable; prevents or reduces the development of antibiotic-resistant bacteria; has a shelf life of over $600 \mathrm{~d}$ at this time (authors' unpubl. data); is relatively cost-effective; and has been used successfully to treat fish topically in small treatment tanks (authors' unpubl. data).

\section{LITERATURE CITED}

Ashworth CD, Nelson DR (1990) Antimicrobial potentiation of irrigation solutions containing tris-(hydroxymethyl) aminomethane-EDTA. J Am Vet Med Assoc 197: 1513-1514

Bayer ME, Leive L (1977) Effect of ethlyenediamintetraacetate upon the surface of Escherichia coli. J Bacteriol 130:1364-1381

Bjorling DE, Wooley RE (1982) EDTA-tromethamine lavage as an adjunct treatment for multiple fistulas in a dog. J Am Vet Med Assoc 181:596-597

Blue JL, Wooley RE, Eagon RG (1974) Treatment of experimentally induced Pseudomonas aeruginosa otitis externa in the dog by lavage with ethylenediaminetetracetate-Tris (hydroxymethyl) aminomethane lysozyme. Am J Vet Res 35:1221-1223

Brown MRW, Richards RME (1965) Effect of ethylenediaminetetraacetate on the resistance of Pseudomonas aeruginosa to antibacterial agents. Nature 207:1391-1393

Bryan LE (1984) Antimicrobial drug resistance. Academic Press, New York, p 255-256

Butler R (1993) The veterinary approach to ornamental fish. In: Brown L (ed) Aquaculture for veterinarians. Pergamon Press, New York

Farca AM, Nebbia P, Re G (1993) Potentiation of the in vitro activity of some antimicrobial agents against selected Gram-negative bacteria by EDTA- tromethamine. Vet Res Comm 17:77-84

Fluit AC, Visser MR, Schmitz FJ (2001) Molecular detection of antimicrobial resistance. Clin Microbiol Rev 14:836-871

Forbes BA, Sahm DF, Weissfeld AS (1998) Bailey \& Scott's diagnostic microbiology, 10th edn. Mosby, St. Louis, p 253-272

Gerberick GF, Castric PA (1980) In vitro susceptibility of Pseudomonas aeruginosa to carbenicillin, glycine, and ethylenediaminetetraacetic acid combinations. Antimicrob Agents Chemo 17:732-735

Goldschmidt MC, Wyss O (1967) The role of tris in EDTA toxicity and lysozyme lysis. J Gen Microbiol 47:421-4310 
Goldschmidt MC, Kuhn CR, Perry K, Johnson DE (1972) EDTA and lysozyme lavage in the treatment of Pseudomonas and coliform bladder infections. J Urol 107:969-972

Heppel LS (1972) Structure and function of biological membranes. Academic Press, New York, p 224-247

Krieg DP, Bass JA, Mattingly SJ (1988) Phosphorylcholine stimulates capsule formation of phosphate-limited mucoid Pseudomonas aeruginosa. Infect Immunol 56:864-873

Leive L (1968) A nonspecific increase in permeability in Escherichia coli produced by EDTA. Proc Natl Acad Sci USA 53:745-750

Leive L, Shovlin VK, Mergenhagen SE (1968) Physical, chemical, and immunological properties of lipopolysaccharide released from Escherichia coli by ethylenediaminetetraacetate. J Biol Chem 243:6384-6391

McNulty ST, Klesius PH, Shoemaker CA, Eans JJ (2002) Streptococcus iniae infection and tissue distribution in hybrid striped bass (Morone crysops $\times$ Morone saxatilis) following inoculation of the gills. ARS, Tektran

Monkhouse DC, Graves GA (1967) The effect of EDTA on the resistance of Pseudomonas aeruginosa to benzalkonium chloride. Aust J Pharmacol 48:570-575

NCCLS (1999) Performance standards for antimicrobial disk and dilution susceptibility tests for bacteria from animals; approved standard M31-A. Vol 19, No 11, NCCLS, Villanova, p 16-25

Roberts NA, Gray GW, Wilkinson SC (1970) The bactericidal action of ethylenediamine-tetra-acetic acid on Pseudomonas aeruginosa. Microbios 7-8:189-208

Russel AD (1967) Effect of magnesium ions and ethylenediaminetetraacetic acid on the activity of vancomycin against Escherichia coli and Staphylococcus aureus. J Appl Bacteriol 30:395-401

Shao ZJ (2001) Aquaculture pharmaceuticals and biologicals: current perspectives and future possibilities. Adv Drug Del Rev 50:231-236

Sparks TA, Kemp DT, Wooley RE, Gibbs PS (1994) Antimicrobial effect of combinations of EDTA-tris and amikacin or neomycin on the microorganisms associated with otitis externa in dogs. Vet Res Comm 18:241-249

Stuart NC (1983) Treatment of fish diseases. Vet Rec 112: 173-177

Walker RD (2000) Antimicrobial susceptibility testing and interpretation of results. In: Prescott JF, Baggot JD, Walker $\mathrm{RD}$ (eds) Antimicrobial therapy in veterinary medicine, 3rd edn. Iowa State University Press, Ames, p 12-26

Weaver-Missick T (1999) Developing new vaccines to prevent

Editorial responsibility: David Bruno,

Aberdeen, UK fish kills. Agricultural Research Service, USDA, Washington, DC

Wooley RE, Blue JL (1975) In vitro effect of EDTA-Trislysozyme on selected pathogenic bacteria. J Med Microbiol 8:189-194

Wooley RE, Jones MS (1983) Action of EDTA-tris and antimicrobial agent combinations on selected pathogenic bacteria. Vet Microbiol 8:271-280

Wooley RE, Schall WD, Eagon RG, Scott TA (1974) Efficacy of EDTA-Tris-lysozyme lavage in the treatment of experimentally induced Pseudomonas aeruginosa cystitis in the dog. Am J Vet Res 35:27-29

Wooley RE, Berman AP, Shotts EB (1979) Antibiotictromethamine-EDTA lavage for the treatment of bacterial rhinitis in a dog. J Am Vet Med Assoc 75:817-818

Wooley RE, Jones MS, Gilbert JP, Shotts EB (1983a) In vitro action of combinations of antimicrobial agents and EDTAtromethamine on Escherichia coli. Am J Vet Res 44: $1154-1158$

Wooley RE, Jones MS, Gilbert JP, Shotts EB (1983b) In vitro action of combinations of antimicrobial agents and EDTAtromethamine on Pseudomonas aeruginosa. Am J Vet Res 44:1521-1524

Wooley RE, Jones MS, Gilbert JP, Shotts EB (1983c) In vitro effect of combinations of antimicrobial agents and EDTAtromethamine on certain Gram-positive bacteria. Am J Vet Res 44:2167-2169

Wooley RE, Jones MS, Gilbert JP, Shotts EB (1984a) In vitro action of combinations of antimicrobial agents with EDTAtromethamine on Proteus vulgaris of canine origin. Am J Vet Res 45:1451-1454

Wooley RE, Jones MS, Shotts EB (1984b) Uptake of antibiotics in Gram-negative bacteria exposed to EDTA-tris. Vet Microbiol 10:57-70

Wooley RE, Sander JE, Maurer JJ, Gibbs PS (2000) In vitro effect of EDTA-tris on the efficacy of hatchery disinfectants. Avian Dis 44:901-906

Wooley RE, Ritchie BW, Kemp DT, Burnley CA (2002) In vitro evaluation of the antimicrobial effect of commercially available mastitis medications combined with EDTA-tris on bacteria that cause mastitis in cattle. Vet Therapeutics: Res Appl Vet Med 3:1-7

Youngquist RS (1975) Pseudomonas metritis in a mare. Vet Med/Small Anim Clin 70:340-342

Youngquist RS, Blanchard TL, Lapin D, Klein W (1984) The effects of EDTA-tris infusion on the equine endometrium. Therogenol 22:593-599

Submitted: October 24, 2003; Accepted: February 6, 2004 Proofs received from author(s): May 3, 2004 